\title{
Photophysical and in vitro Antibacterial Studies of 2,6-Dibromo- BODIPY Dye Substituted with Dithienylenevinylene at 3,5-Positions
}

\author{
B. T. Bomanda, ${ }^{a}$ W. Waudo, ${ }^{\mathrm{b}}$ B. P. Ngoy, ${ }^{\mathrm{a}}{ }^{@}$ J. T. Muya, ${ }^{a}$ P. T. Mpiana, ${ }^{\mathrm{a}}$ M. Mbala, ${ }^{\mathrm{a}}$ \\ I. Openda, ${ }^{\mathrm{a}}$ J. Mack, ${ }^{\mathrm{c}}$ and T. Nyokong ${ }^{\mathrm{c}}$
}

Dedicated to Prof. Ilinga Lopaka on the occasion of his $70^{\text {th }}$ Birthday

\begin{abstract}
a'Département de Chimie, Université de Kinshasa, B.P. 190 KIN XI, Democratic Republic of the Congo
bomo Kenyatta University of Agriculture and Technology, Chemistry Department, P.O. Box 62000 Nairobi, Kenya

'Department of Chemistry, Rhodes University, 6140 Grahamstown, South Africa

${ }^{\circledR}$ Corresponding author E-mail: bokolombe@gmail.com
\end{abstract}

\begin{abstract}
Photophysical properties of synthesized 2,6-brominated BODIPY dyes having dithienylenevinylene at 3,5-positions have been investigated in different solvents combining experiment and time dependent density functional theory (TD$C A M-B 3 L Y P)$. This study shows a good agreement between the measured and computed excitation energies with a small deviation of 25-40 $\mathrm{nm}$. The UV-Visible range corresponding to the electronic transition involving HOMO, HOMO1 and LUMO orbitals is also reported. Further, the assessment of the antimicrobial activity of the 2,6-brominated BODIPY and 2,6-brominated BODIPY substituted with distyryl at 3,5-postions has shown that at lower concentrations $\left(3.12 \cdot 10^{-3} \mathrm{mg} / \mathrm{mL}\right)$ these synthesized compounds are able to eradicate E. coli and $S$. aureus upon 25 minutes irradiation using LEDs shining light at $530 \mathrm{~nm}$ and $650 \mathrm{~nm}$.
\end{abstract}

Keywords: Brominated BODIPY, protein disulfide isomerase (PDI), singlet oxygen, quantum yield, fluorescence, TD-DFT.

\section{Фотофизические и антибактериальные in vitro исследования 2,6-Аибром-BODIPY красителя, замещенного Аитиениленвиниленом в положениях 3, 5}

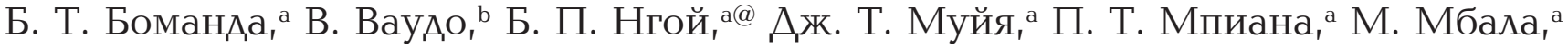 \\ И. Опенда, ${ }^{\mathrm{a}} \mathrm{A}$ ж. Мак, ${ }^{\mathrm{c}}$ Т. Ниоконг ${ }^{\mathrm{c}}$ \\ а Химический факультет, Университет Киншасы, В.P. 190 KIN XI, Демократическая республика Конго \\ ${ }^{\mathrm{b}}$ Университет сельского хозяйства и технологий Джоми Кеньятты, Химический факультет, а/я 62000 Найроби, Кения \\ 'Химический факультет, Университет Родса, 6140 Грейамстаун, ЮАР \\ ${ }^{\circledR}$ E-mail: bokolombe@gmail.com
}

\begin{abstract}
Получень 2,6-дибром-ВОDІРY красители с дитиениленвинилен-группами в положениях 3 и 5 . Изучень их фотофизические свойства в различных растворителях с привлечением эксперимента и теории (временнозависимой теории функционала плотности, ТD-САМ-В3LYP). Это исследование демонстрирует хорошую согласованность измеренных и вычисленных энергий возбуждения с небольшим отклонением (25-40 нм). Рассмотрены диапазоны электронных спектров поглощения, соответствующие электронным переходам с участием ВЗМО, ВЗМО-1 и НВМО. Оченка противомикробной активности 2, 6-бромированного ВОDIPY и его 3,5-дистирилпроизводного показала, что при низких концентрациях $\left(3.12 \cdot 10^{-3} \mathrm{Mz} / \mathrm{Mл}\right)$ эти соединения способны уничтожать E. coli u S. аитеиs при 25-минутном облучении с использованием светодиодов, излучающих свет при 530 нм и 650 нм.
\end{abstract}

Ключевые слова: Бромированный BODIPY, протеин-дисульфид изомераза, синглетный кислород, квантовый выход, флуоресценция, TD-DFT. 


\section{Introduction}

The use of dyes by researchers becomes one of the alternative ways to solve problems in army, environment, solar cells construction, medicine including chemistry and biochemistry. Applications such as water treatment, photodynamic therapy (PDT), photodynamic antimicrobial chemotherapy (PACT), dye sensitization solar cells, nonlinear optic properties of these dyes are investigated nowadays. ${ }^{[1-3]}$ Dyes such as phthalocyanines, metallophthalocyanines, porphyrins, BODIPY, coumarins and others are used for that purpose ${ }^{[4-7]}$ but some of them are mostly used as photosensitizers in water treatment, PDT, and bacteria photodynamic inactivation in combination of oxygen and light. ${ }^{[8-11]}$ Generation of singlet oxygen by energy transfer in triplet state between the photosensitizer and the ground state oxygen is the key of the success of these kind of processes. Photodynamic antimicrobial chemotherapy (PACT) also called antimicrobial PDT was expected to be among the new antimicrobial techniques that do not rely neither in cell biology approaches nor in selective pharmacology. ${ }^{[12,13]}$ Neutral and cationic modified BODIPY dyes have been used and evaluated in vitro and in vivo for PACT ${ }^{[14-16]}$ and still many works are under investigations. The attempt is about to find an alternative way of killing bacteria or microorganisms which seem to become resistant to the known antibiotics. In this paper we report the photophysical properties studies and in vitro antibacterial activity evaluation of the 2,6-brominated BODIPY alone and the 2,6-brominated BODIPY conjugated at positions 3 and 5 with 3-thiophenecarboxaldehyde as potential photosensitizers against Staphylococcus aureus and Escherichia coli. The TD-CAM-BLYP/6$31 \mathrm{G}(\mathrm{d})$ calculations to evaluate the singlet excitation energies of BODIPY compounds were carried out. The fluorescence and UV-Vis spectra including the heavy atom effect in increasing the intersystem crossing leading to the production of more singlet oxygen ${ }^{[17]}$ and the extension of $\pi$-systems are demonstrated in this work.

\section{Experimental}

\section{Materials}

2,4-Dimethylpyrrol, 3-thiophenecarbaldehyde, $N$-bromosuccinimide, trifluoroacetic acid, $p$-chloranil, triethylamine, boron trifluoride diethyl etherate, acetic acid, piperidine, 1,3-diphenylisobenzofuran (DPBF) were commercially available, purchased from Sigma-Aldrich and used without any purification. Dried dichloromethane and benzene were used as solvents for synthesis. Staphylococcus aureus and Escherichia coli cells were isolated urines of infected people and identified at University of Kinshasa Hospital in Democratic Republic of Congo.

\section{Equipment}

Ground state electronic absorption spectra were performed on a Shimadzu UV-2550 spectrophotometer while fluorescence excitation and emission spectra were obtained on a Varian Eclipse spectrofluorimeter. The absorbance of the vibronic bands ranged between 0.04 and 0.05 at the excitation wavelength for emission studies. ${ }^{1} \mathrm{H}$ NMR spectra were recorded in a Bruker $600 \mathrm{MHz}$ and deuterated THF or chloroform were used as solvent. Elemental analyses were performed on a Vario EL III MicroCube CHNS Analyzer. Mass spectrometry was performed using a Bruker AutoFLEX III Smartbeam MALDI-TOF mass spectrometer. Time-correlation single photon counting device equipped with a Picoquant $\mathrm{GmbH}$ containing a LDH-P-670 diode laser with a 44 ps pulse width and $20 \mathrm{MHz}$ rate repetition was used for fluorescence lifetimes determination where an exponential decay curves were analyzed by using Picoquant's Fluofit software package. Singlet oxygen quantum yield determination was done using a tunable laser system consisting of a Quanta-Ray Nd:YAG laser (355 nm, 135 mJ/4-6 ns) pumping an optical parametric oscillator (OPO, $30 \mathrm{~mJ} / 3-5 \mathrm{~ns}$ ) with a wavelength range of 420-2300 nm (NT-342B, Ekspla). Solutions of photosensitizer containing DPBF were prepared in the dark and irradiated using the setup described above. DPBF degradation around $415 \mathrm{~nm}$ was monitored. Irradiation for PDI studies was conducted using green and red LED with emissions at $530 \mathrm{~nm}$ and $650 \mathrm{~nm}$, respectively.

\section{Fluorescence quantum yield $\left(\Phi_{F}\right)$}

The fluorescence quantum yields of the conjugated BODIPY dye were obtained using the comparative method, using Equation 1:

$$
\phi_{F}=\phi_{F(s t d)} \frac{F A_{s t d} \eta^{2}}{F_{s t d} A \eta_{s t d}^{2}},
$$

where $F$ and $F_{\text {std }}$ are the integrated fluorescence intensities of the BODIPY complexes and the standard, respectively. The integrated fluorescence intensity is equal to the area beneath a fluorescence emission curve. $A$ and $A_{\text {std }}$ are the absorbances of the samples and standard, respectively. Zinc phthalocyanine was used as standard with known values ( $\Phi_{\mathrm{F}}=0.20$ in DMSO, 0.17 in DMF, 0.23 in THF, and 0.28 in ethanol). ${ }^{[18-20]}$ The standard and samples were both excited at the same wavelength.

\section{Singlet oxygen quantum yield $\left(\Phi_{\Delta}\right)$}

The singlet oxygen quantum yields $\left(\Phi_{\Delta}\right)$ of the BODIPY dye were studied in a spectrophotometric cell of $1 \mathrm{~cm}$ path length. Quantum yields of singlet oxygen photogeneration were determined in DMF, DMSO, THF and EtOH solutions (in air without bubbling oxygen) using the relative method with zinc phthalocyanine ( $\mathrm{ZnPc})$ as reference and DPBF (1,3-diphenylisobenzofuran) as chemical quencher for singlet oxygen. ${ }^{[21]}$ Solutions of the sample and reference photosensitizers (absorbance below 0.5 at irradiation wavelength) containing DPBF were prepared in the dark and irradiated at the crossover wavelength using a laser. Depending on the crossover wavelength, singlet oxygen determination was done at $682,674,662$, and $672 \mathrm{~nm}$ for DMSO, DMF, THF, and ethanol, respectively. DPBF absorption decay around $415 \mathrm{~nm}$ was monitored. The values of $\Phi_{\Delta}$ were calculated using Equation 2:

$$
\phi_{\Delta}=\phi_{\Delta}^{Z n P c} \frac{R I_{a b s}^{Z n P c}}{R^{Z n P c} I_{a b s}},
$$

where $\Phi_{\Delta}{ }^{Z n P c}$ is the known singlet oxygen quantum yield for $\mathrm{ZnPc}$ in different solvents used in this work $\left(\Phi_{\Delta}=0.67\right.$ in DMSO, 0.56 in DMF, 0.53 in THF, and 0.53 in ethanol using $0.3 \%$ of pyridine for solubility) ${ }^{[22-25]} R$ and $R^{Z n P c}$ are the DPBF photodegradation rates in the presence of $\mathbf{3}$ and in the presence of $\mathrm{ZnPc}$, respectively. $I_{a b}$ and $I_{a b s}{ }_{n \rightarrow c}$ are the rates of light absorption by the sample and $\mathrm{ZnPc}$, respectively. The initial DPBF concentrations were kept the same for both the $\mathrm{ZnPc}$ reference and the sample.

\section{Synthesis}

1,3,5,7-Tetramethyl-8-(4-bromophenyl)-4,4'-difluoroboradiaza indacene (1). Freshly distilled 2,4-dimethylepyrrole (2 g, 
$21.02 \mathrm{mmol}$ ) and 4-bromobenzaldehyde (1.94 g, $10.05 \mathrm{mmol})$ were dissolved in $\mathrm{CH}_{2} \mathrm{Cl}_{2}(100 \mathrm{~mL})$ under argon and a catalytic amount $(0.3 \mathrm{~mL})$ of trifluoroacetic acid was added to the mixture. After stirring the mixture for about 40 minutes allowing the 4-bromobenzaldehyde to be consumed at room temperature $p$-chloranil (3.88 g, $15.77 \mathrm{mmol})$ dissolved in DCM $(10 \mathrm{~mL})$ was added via syringe at $0^{\circ} \mathrm{C}$ and the mixture was stirred at room temperature for another 40 minutes before the addition of triethylamine (10.64 $\mathrm{g}, 105.10 \mathrm{mmol})$ and $\mathrm{BF}_{3} \cdot \mathrm{OEt}_{2}(17.90 \mathrm{~g}, 126.12 \mathrm{mmol})$ at $0^{\circ} \mathrm{C}$. The mixture was stirred overnight at room temperature. The resulting crude mixture was filtered, washed with water and dried over $\mathrm{Na}_{2} \mathrm{SO}_{4}$. After evaporation using a rotavapor the residue was purified by column chromatography using petroleum etherethylacetate $(4: 1 \mathrm{v} / \mathrm{v})$ to afford $40 \%$ of $\mathbf{1}$. UV-Vis $\left(\mathrm{CH}_{2} \mathrm{Cl}_{2}\right) \lambda_{\text {max }}$ nm: 502. ${ }^{1} \mathrm{H}$ NMR $\left(600 \mathrm{MHz}, \mathrm{CDCl}_{3}\right) \delta_{\mathrm{H}} \mathrm{ppm}: 7.64(\mathrm{~d}, J=8.3 \mathrm{~Hz}$, 2H), 7.20 (d, J=8.4 Hz, 2H), 6.02 (s, 2H), 2.58 (s, 6H), 1.44 (s, 6H).

2,6-Dibromo-BODIPY dye (2). To a solution of $\mathbf{1}(0.820 \mathrm{~g}, 1$ eq) in dichloromethane $(50 \mathrm{~mL})$ was added $N$-bromosuccinimide $(0.869 \mathrm{~g}, 2.4 \mathrm{eq})$. The mixture was stirred under argon at room temperature for two hours following by TLC. The solvent was evaporated and the titled compounds were obtained with $35 \%$ yield after purification with the system petroleum etherethylacetate $(4: 1 \mathrm{v} / \mathrm{v})$. MALDI-TOF $(\mathrm{M}+\mathrm{H})$ : Calc: 560.86 , found: 561.0. UV-Vis $\left(\mathrm{CH}_{2} \mathrm{Cl}_{2}\right) \lambda_{\text {max }} \mathrm{nm}: 528 .{ }^{1} \mathrm{H} \mathrm{NMR}\left(600 \mathrm{MHz}, \mathrm{CDCl}_{3}\right)$ $\delta_{\mathrm{H}}$ ppm: $7.71(\mathrm{~d}, J=8.3 \mathrm{~Hz}, 2 \mathrm{H}), 7.18(\mathrm{~d}, J=8.4 \mathrm{~Hz}, 2 \mathrm{H}), 2.63(\mathrm{~s}, 6 \mathrm{H})$, $1.44(\mathrm{~s}, 6 \mathrm{H})$.

2,6-Dibromo-3,5-distyryl BODIPY dye (3). To a solution of dibromo-3,5-BODIPY (2) (0.75 g, 1 eq) and 3-thiophenecarbaldehyde $(0.299 \mathrm{~g}, 2 \mathrm{eq})$ in benzene $(75 \mathrm{~mL})$ was added glacial acetic acid $(1.2 \mathrm{~mL})$ and piperidine $(1.2 \mathrm{~mL})$. The mixture was allowed to reflux for about two hours using Dean-Stark apparatus to remove any amount of water being formed during the reaction. The concentrated crude was diluted with dichloromethane, washed with hydrochloric acid, sodium hydrogen carbonate and brine, respectively. The title compounds were obtained with $20 \%$ yield after purification with the system dichloromethane-ethylacetate $(1: 4 \mathrm{v} / \mathrm{v})$. Calc for $\left[\mathrm{C}_{20} \mathrm{H}_{20} \mathrm{BBr}_{3} \mathrm{~N}_{2} \mathrm{~S}_{2}\right]$ : C 46.50, H 2.69, N $3.74 \%$. Found: C 45.97, H 2.876, N 3.44, S 7.480 \%. MALDI-TOF (M+H): Calc: 749 , found: 750 . UV-Vis $\left(\mathrm{CH}_{2} \mathrm{Cl}_{2}\right) \lambda_{\max } \mathrm{nm}: 650 .{ }^{1} \mathrm{H}$ NMR $\left(600 \mathrm{MHz}, \mathrm{THF}-d_{8}\right) \delta_{\mathrm{H}}$ ppm: $8.31(\mathrm{~d}, J=16.6 \mathrm{~Hz}, 2 \mathrm{H}), 7.92(\mathrm{~d}$, $J=6.6 \mathrm{~Hz}, 2 \mathrm{H}), 7.81(\mathrm{~s}, 2 \mathrm{H}), 7.73$ (d, $J=16.7 \mathrm{~Hz}, 2 \mathrm{H}), 7.62$ (d, $J=2.0 \mathrm{~Hz}, 4 \mathrm{H}), 7.51$ (d, $J=8.3 \mathrm{~Hz}, 2 \mathrm{H}), 1.62$ (s, 6H).

\section{Evaluation of antibacterial activity}

\section{Bacterial inoculum}

Escherichia coli and Staphylococcus aureus were selected as microorganisms in this study. A 24-hours culture broth were used to prepare the inoculum, where a 1/500 dilution were used for Gram-positive (S. aureus) and a 1/5000 dilution for gramnegative (E. coli). Sterilized physiological saline in a haemolysis tube was added and pure colonies were collected and suspended until the same opacity was obtained as the Mac Farland 0.5 standard.

\section{Agar diffusion method}

A disc is impregnated in the BODIPY solution, then deposited in the antibiogram medium containing the seeds prepared according to Mac Farland method, then incubated at $37^{\circ} \mathrm{C}$ for $24 \mathrm{~h}$. The clear areas present are measured using a ruler and compared with a diameter of inhibition of a reference antibiotic. The culture medium were prepared according to the theoretical formula where strains were seeded with tight streaks using a sterile swab and previously impregnated discs were deposited the in the solution of BODIPY dyes at different concentrations where the stock solutions were prepared by using $1 \%$ of DMSO followed by $99 \%$ of water.

\section{Dilution method}

Dilutions were then performed in order to find the Minimum Inhibitory Concentration (MIC) after a serial dilution of the BODIPY in a series of tubes numbered $\mathrm{T}_{0}, \mathrm{~T}_{1}, \mathrm{~T}_{2}, \mathrm{~T}_{3}$ and $\mathrm{T}_{4}$. All tubes were sealed with wadding to avoid any contamination and a drop of the inoculum was added in each numbered tubes and incubated at $37^{\circ} \mathrm{C}$ for 24 hours.

\section{Activation of the solution of each BODIPY containing the germs}

Each tube containing the BODIPY solution at different concentrations was subjected to irradiation depending on the BODIPY absorption wavelength, i.e. $530 \mathrm{~nm}$ light dose $10 \mathrm{~J} / \mathrm{cm}^{2}$ and $650 \mathrm{~nm}$ light dose $77 \mathrm{~J} / \mathrm{cm}^{2}$ for compound $\mathbf{2}$ and $\mathbf{3}$, respectively. The maximum irradiation time was $25 \mathrm{~min}$ and the results were compared with those of the solutions in dark.
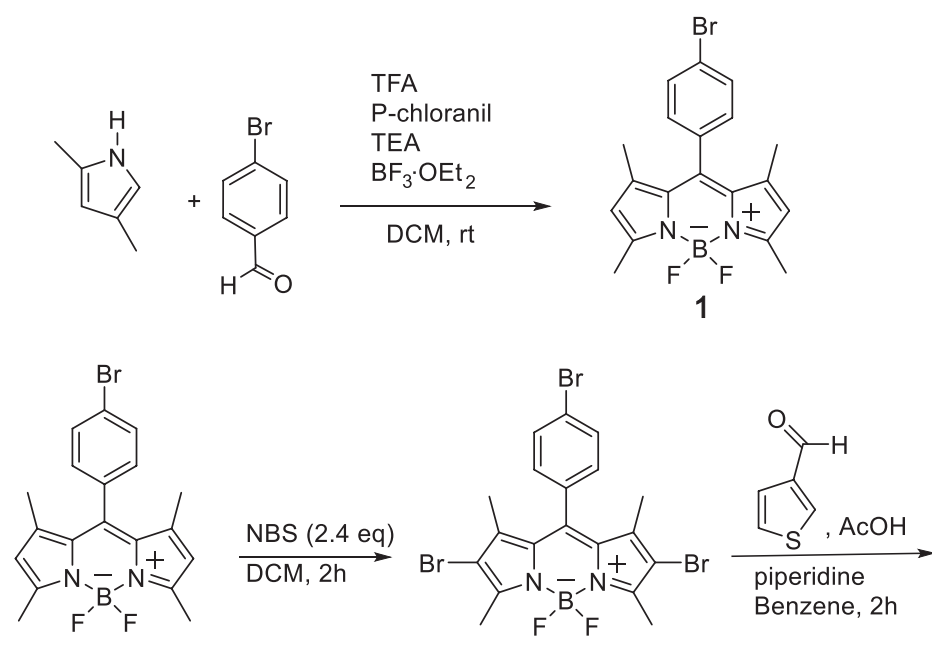

2

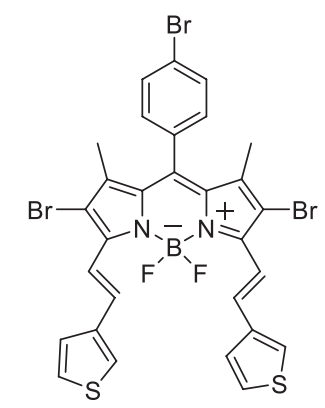

Scheme 1. Synthesis of BODIPY dyes. 


\section{Computational method}

The ground state electronic structures of BODIPY were carried out using CAM-B3LYP exchange-correlation functional at 6-31G(d) level. The optical absorption spectra of BODIPY were computed using the time dependent density functional theory, TDCAM-B3LYP/6-31G(d), in vacuo and in dichloromethane. This method was used previously by Ngoy et al. ${ }^{[26]}$ on similar molecules and have shown to provide optical properties close to experiment. The theoretical background of time-dependent density functional theory is described elsewhere. ${ }^{[27]}$ The effect of the solvent on the optical properties of BODIPY was studied using the quantum mechanical polarizable continuum solvation model $(\mathrm{PCM}){ }^{[28]}$ All the quantum chemical calculations in the present study were performed using the Gaussian 09 software package. ${ }^{[29]}$

\section{Results and Discussion}

\section{Synthesis}

Brominated and conjugated BODIPY dyes (2, 3) were synthesized following the literature. ${ }^{[30-32]}$ Two steps experimental procedure from the BODIPY core such as halogenation and Knoevenagel condensation were used to afford desired compounds with $35 \%$ yield for brominated and $20 \%$ for the styryl BODIPY (Scheme 1).

\section{Absorption and fluorescence spectra}

Figures 1-2 show the UV-Vis absorption spectra and normalized excitation and emission spectra of compound 3 in different solvents. Absorption and excitation spectra have maximum in the range of 645-650 $\mathrm{nm}$ while the maxima for compound 2 in $\mathrm{CH}_{2} \mathrm{Cl}_{2}$ is around $528 \mathrm{~nm}$ (see Figure S3). These results confirm that conjugation at 3,5-positionsis sufficient to cause bathochromic shift in the UV-Vis spectra of BODIPY dyes. These maximum wavelengths were also found for other kind of 3,5-dithienylenevinylene BODIPY dyes. ${ }^{[33]}$ Recently, we have reported that when the styrylation is done between compound 2 and $p$-benzyloxybenzaldehyde, the distyryl formed had a maximum absorption around $666 \mathrm{~nm}$ in dichloromethane. ${ }^{[34]}$ However, emissions are approximately around 665-675 $\mathrm{nm}$ and these BODIPY are suggested to be useful in antimicrobial photodynamic inactivation of bacteria and for photodynamic therapy as long as they are absorbing in the therapeutic window $(620-850 \mathrm{~nm})$.

\section{Photophysical properties}

$N, N$-Dimethylformamide (DMF), dimethylsulfoxide (DMSO), ethanol (EtOH) and tetrahydrofuran (THF) were used as solvents for the determination of spectroscopic

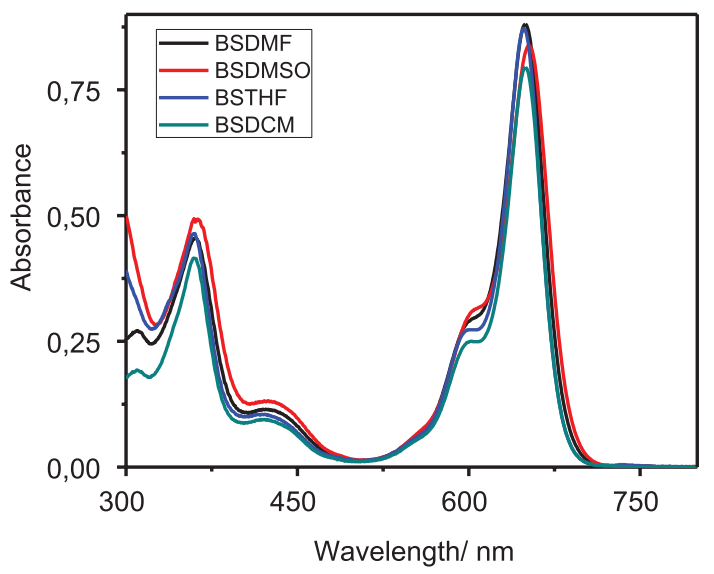

Figure 1. UV-Visible absorption spectra of 3 in DMF, DMSO, THF, and $\mathrm{CH}_{2} \mathrm{Cl}_{2}$.

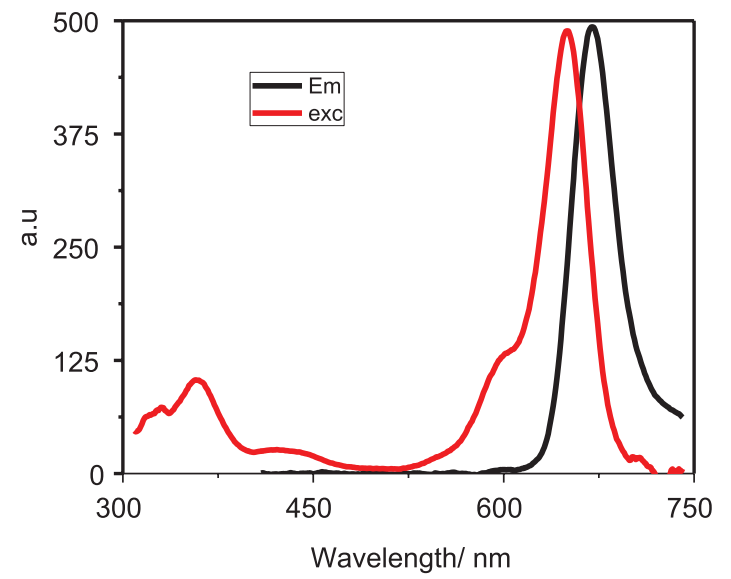

Figure 2. Excitation (red) and emission (black) spectra of 3 in DMF.

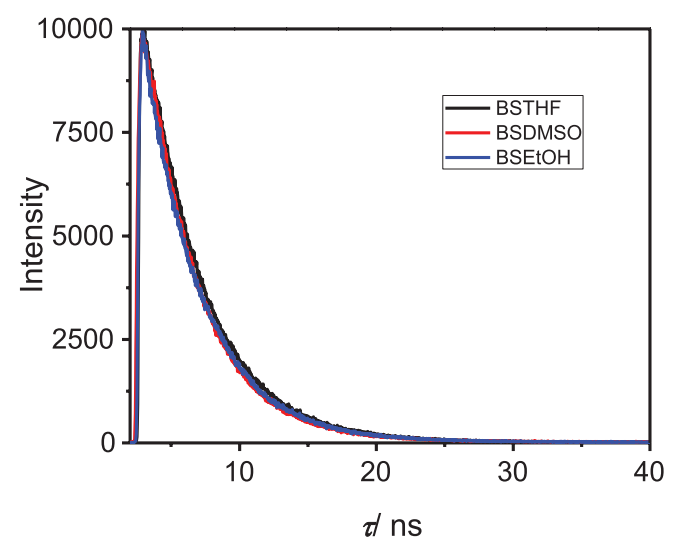

Figure 3. Fluorescence decay of $\mathbf{3}$ in THF, DMSO, and EtOH.

Table 1. Photophysical properties of BODIPY 3 in different solvents.

\begin{tabular}{ccccccc}
\hline Solvent & $\lambda_{\mathrm{ex}}, \mathrm{nm}$ & $\lambda_{\mathrm{em}}, \mathrm{nm}$ & Stokes shift, $\mathrm{nm}$ & $\tau_{1}, \mathrm{~ns}$ & $\Phi_{f}$ & $\Phi_{\Delta}$ \\
\hline DMF & 650 & 670 & 21 & $3.52 \pm 0.02$ & $0.32 \pm 0.01$ & $0.28 \pm 0.02$ \\
DMSO & 654 & 675 & 21 & $3.76 \pm 0.02$ & $0.25 \pm 0.03$ & $0.35 \pm 0.01$ \\
EtOH & 650 & 669 & 19 & $4.11 \pm 0.03$ & $0.30 \pm 0.02$ & $0.22 \pm 0.03$ \\
THF & 647 & 665 & 18 & $4.16 \pm 0.01$ & $0.35 \pm 0.01$ & $0.20 \pm 0.03$ \\
\hline
\end{tabular}




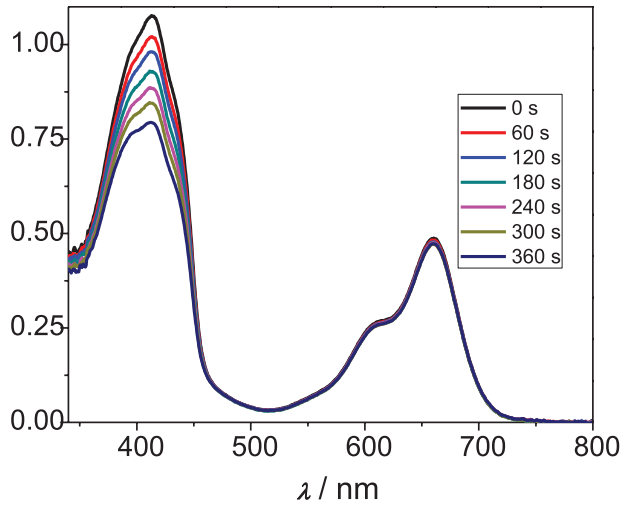

Figure 4. Spectra showing the irradiation mixture of $\mathbf{3}$ and DPBF in DMF for six minutes.

data of BODIPY conjugated with 3-thiophenecarbaldehyde and the results are shown in Table 1. From this table it can be seen that compound $\mathbf{3}$ shows a good singlet oxygen quantum yield (0.35) in DMSO compared to DMF (0.28), EtOH (0.22), and THF $(0.20)$. This trend especially in the case of DMSO and DMF was also observed and reported by B.P. Ngoy et al. for BODIPY dyes conjugated with 4-benzyloxystyryl. ${ }^{[26]}$

In the other hand, the trend of the fluorescence quantum yields was shown to be in the reverse way. Similar results were found and reported by J. Harris et al. in DMF. ${ }^{[33]}$ However, fluorescence lifetimes are almost the same and in the nanosecond timescale and lie in the 3.54.2 ns. The heavy atom effect of bromines capable of increasing the intersystem crossing quantum yield by spinorbit coupling was demonstrated. Further studies about incorporation or linkage of nanoparticle with sulfur could help for the enhancement of singlet oxygen photogeneration.

Singlet oxygen generation was indirectly confirmed by decomposition of its specific scavenger DPBF that was followed by decrease of DPBF absorption after irradiation of the BODIPY samples (Figure 4).

\section{Evaluation of antibacterial activity}

Antibacterial studies were conducted using compounds $\mathbf{2}$ and $\mathbf{3}$ and activities were tested toward 25 minutes irra- diation at different concentrations. From the results shown in Figures 5, 6 it is clearly shown that at certain concentrations the antimicrobial activity of the selected compounds are non-negligible. Minimum Inhibitory Concentrations (MIC) were around $12.5 \cdot 10^{-3} \mathrm{mg} / \mathrm{mL}$ for 2 against $E$. coli and $6.25 \cdot 10^{-3} \mathrm{mg} / \mathrm{mL}$ against $S$. aureus. However, compound 3 showed $6.25 \cdot 10^{-3} \mathrm{mg} / \mathrm{mL}$ against $E$. coli and $3.12 \cdot 10^{-3} \mathrm{mg} /$ $\mathrm{mL}$ against $S$. aureus. Compound $\mathbf{2}$ exhibits some promising antibacterial activities at low concentration $\left(3.12 \cdot 10^{-3} \mathrm{mg} /\right.$ $\mathrm{mL})$ after irradiation for both E. coli and S. aureus $(8 \mathrm{~mm})$ against $(5 \mathrm{~mm})$ in dark. The similar gap is observed at high concentration $0.1 \mathrm{mg} / \mathrm{mL}(16 \mathrm{~mm}$ versus $13 \mathrm{~mm})$ for E. coli, and $(17 \mathrm{~mm}$ versus $14 \mathrm{~mm})$. This activity can be attributed to the enhancement of singlet oxygen quantum yield due to heavy atom effect from bromine atoms. ${ }^{[37-38]}$

Compound 3, around $3.12 \cdot 10^{-3} \mathrm{mg} / \mathrm{mL}$, is showing similar inhibition zone diameters $(9 \mathrm{~mm})$ for all of the microorganisms used when the diffusion method on agar is used but in dark, activities are around $5 \mathrm{~mm}$ for $E$. coli and $6 \mathrm{~mm}$ for $S$. aureus. It was already reported that BODIPY dyes $(0.5-5 \mu \mathrm{M})$ were able to inactivate $E$. coli and $S$. xylosus. ${ }^{[14]}$

However, looking at the results when diffusion method on Mannitol Salt Agar and Mac Conkey agar is used (Figure 7), the antibacterial activity is around $24 \mathrm{~mm}$ for E. coli when a solution of BODIPY $5 \cdot 10^{-2} \mathrm{mg} / \mathrm{mL}$ is used and the behavior is not the same compare to dark solutions at that concentration. However, at $0.1 \mathrm{mg} / \mathrm{mL}$ a higher inhibition zone diameter around $26 \mathrm{~mm}$ is seen for the photosensitizer 3 towards E. coli and $15 \mathrm{~mm}$ for $S$. aureus although in dark, the toxicity is some how pronounced around $16 \mathrm{~mm}$ and $14 \mathrm{~mm}$ for $E$. coli and $S$. aureus, respectively. To our best of knowledge there is a good literature about the efficiency of BODIPY dyes against gram positive bacteria over gram negative bacteria. ${ }^{[35-36]}$ The lipophilicity of the brominated BODIPY dye and the conjugated BODIPY dyes containing sulfur and bromine atoms was one of the disvantages of this study but solutions were dissolved in $1 \%$ DMSO and $99 \%$ distilled water.

\section{Theoretical calculations}

Atomic labels and the equilibrium geometries of BODIPY denoted as $\mathbf{1}, \mathbf{2}, \mathbf{3 a}$, and $\mathbf{3 b}$ used in the present work are shown in Figure S2 (Supporting information).
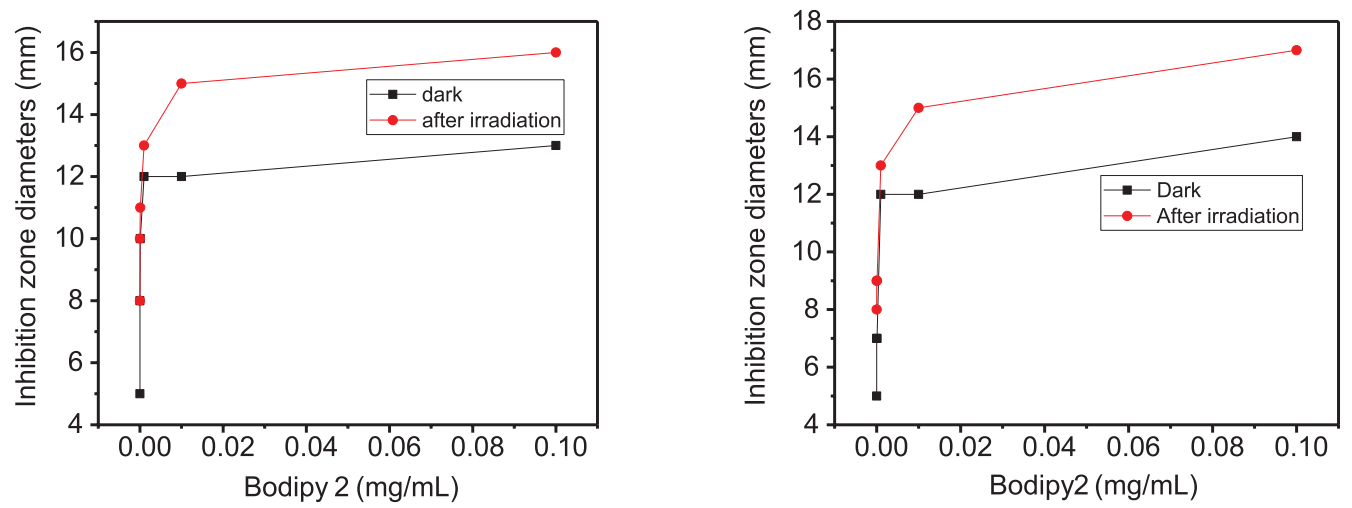

Figure 5. Photodynamic inactivation of Escherichia coli (left) and Staphylococcus aureus (right) cultures following diffusion method on MSA and Mac Conkey agar at different concentrations of $\mathbf{2}$ in dark and after irradiation using $530 \mathrm{~nm}$ LED (60 mW). 

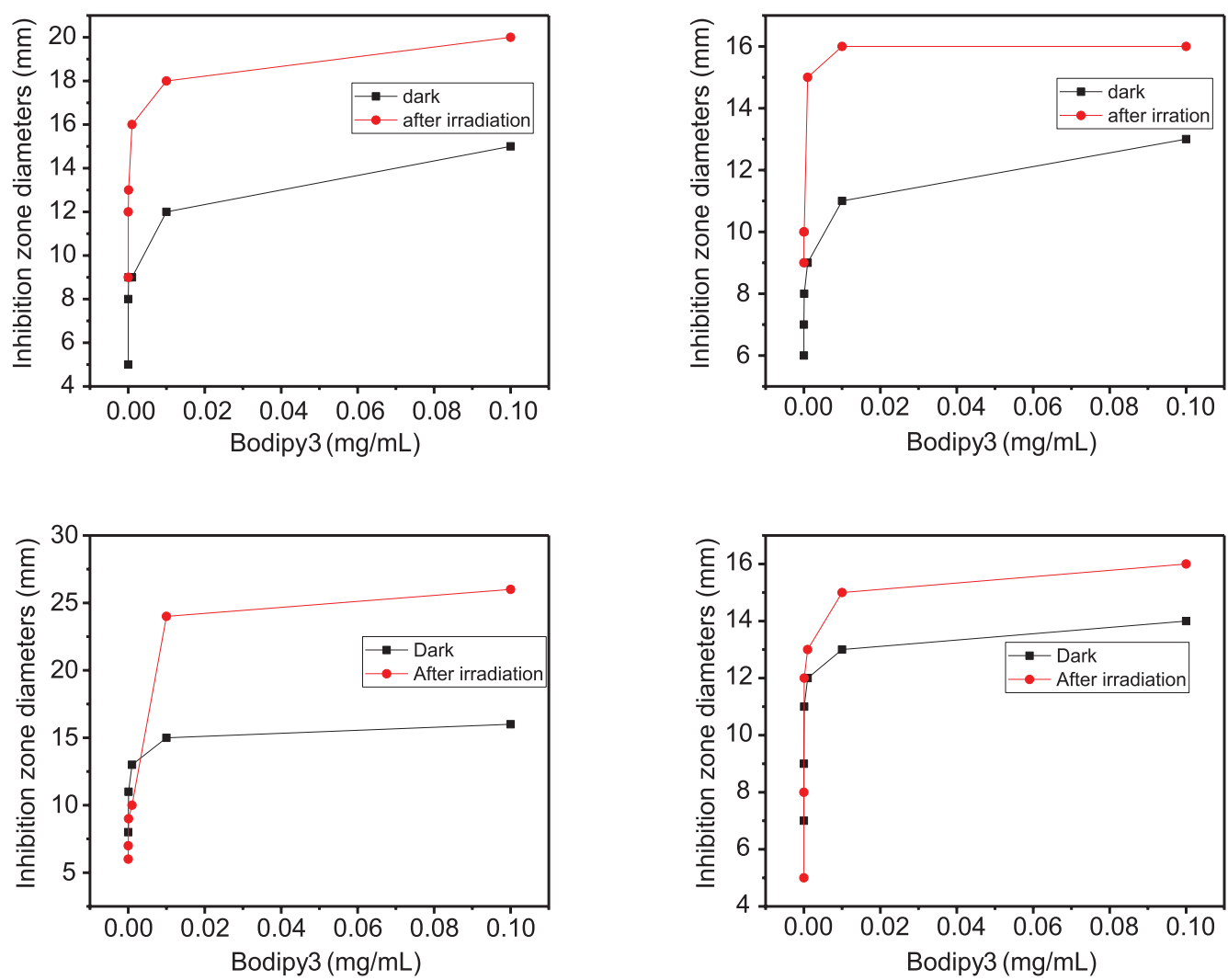

Figure 6. Photodynamic inactivation of Escherichia coli (left) and Staphylococcus aureus (right) cultures following diffusion method on MH agar (up) and diffusion method on MSA and Mac Conkey agar (down) at different concentrations of $\mathbf{3}$ in dark and after irradiation using $650 \mathrm{~nm}$ LED $(60 \mathrm{~mW})$.

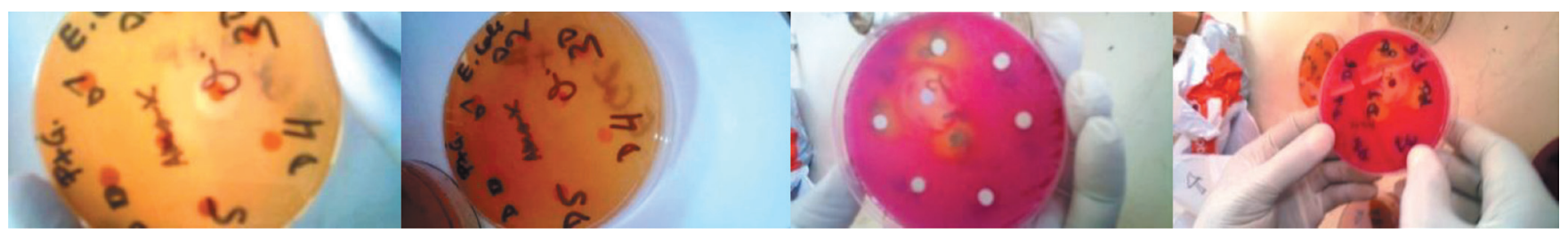

Figure 7. Growth inhibition of $S$. aureus and E. coli strains, respectively, caused by $\mathbf{2}$ (left) and $\mathbf{3}$ (right).

Table 2. Frontier molecular orbital energies in a.u (Hartrees) and HOMO-LUMO gaps (H-L in eV) of the ground states of 1-3 computed at CAM-B3LYP/6-31G(d).

\begin{tabular}{ccccc}
\hline MOS & $\mathbf{1}$ & $\mathbf{2}$ & $\mathbf{3 a}$ & $\mathbf{3 b}$ \\
\hline L+2 & 0.01499 & 0.00737 & 0.00279 & 0.00338 \\
L+1 & 0.01474 & 0.00582 & -0.00873 & -0.00927 \\
L & -0.07161 & -0.08754 & -0.08549 & -0.0862 \\
H & -0.26436 & -0.27327 & -0.23239 & -0.23174 \\
H-1 & -0.30765 & -0.31142 & -0.27035 & -0.27031 \\
H-2 & -0.31564 & -0.31979 & -0.29563 & -0.29613 \\
H-3 & -0.32322 & -0.32 & -0.30317 & -0.30296 \\
H-L gap & 5.24 & 5.05 & 4.00 & 3.96 \\
\hline
\end{tabular}

Structure 2 was obtained from 1 after substitition of $\mathrm{H}$ atoms involved in $\mathrm{C} 10-\mathrm{H}$ and $\mathrm{C} 5-\mathrm{H}$ bonds by $\mathrm{Br}$ atoms. Further, $\mathrm{H}$ in $\mathrm{C} 4-\mathrm{H}$ and $\mathrm{C} 5-\mathrm{H}$ bonds were replaced by $\mathrm{CHCHC} 4 \mathrm{H} 3 \mathrm{~S}$ atoms group. The optimized orientation of $\mathrm{CHCHC} 4 \mathrm{H} 3 \mathrm{~S}$ in $\mathbf{3} \mathbf{a}$ and $\mathbf{3} \mathbf{b}$ was obtained after $1 \mathrm{D}$ scan of the torsion angle $\mathrm{C} 4-\mathrm{C} 34-\mathrm{C} 35-\mathrm{C} 38$. The analysis of the geometric and energetic parameters of different isomers of $\mathbf{3}$ show $\mathbf{3} \mathbf{a}$ and $\mathbf{3} \mathbf{b}$ structures to be the lowest and be characterized by weak C-H...Br bonds. Isomer $\mathbf{3 a}$ lies below 3b by $1.01 \mathrm{kcal} / \mathrm{mol}$ including the zero-point vibrational energy. These isomers are characterized by weak C-H...F bonds of about 2.19 and $2.81 \AA$ for $3 \mathbf{a}$ and 2.05 and $2.66 \AA$ for $\mathbf{3 b}$. $\mathrm{CHCHC} 4 \mathrm{H} 3 \mathrm{~S}$ atoms group prefers to be orientated in trans conformer rather than in cis. The electronic energy difference between 3a and 3c (referred as trans and cis) reveals that the cis orientation will cost about $6.59 \mathrm{kcal} / \mathrm{mol}$ in vacuo and is unlikely to be observed experimentally. The energies of high-laying occupied orbitals and that of low- 


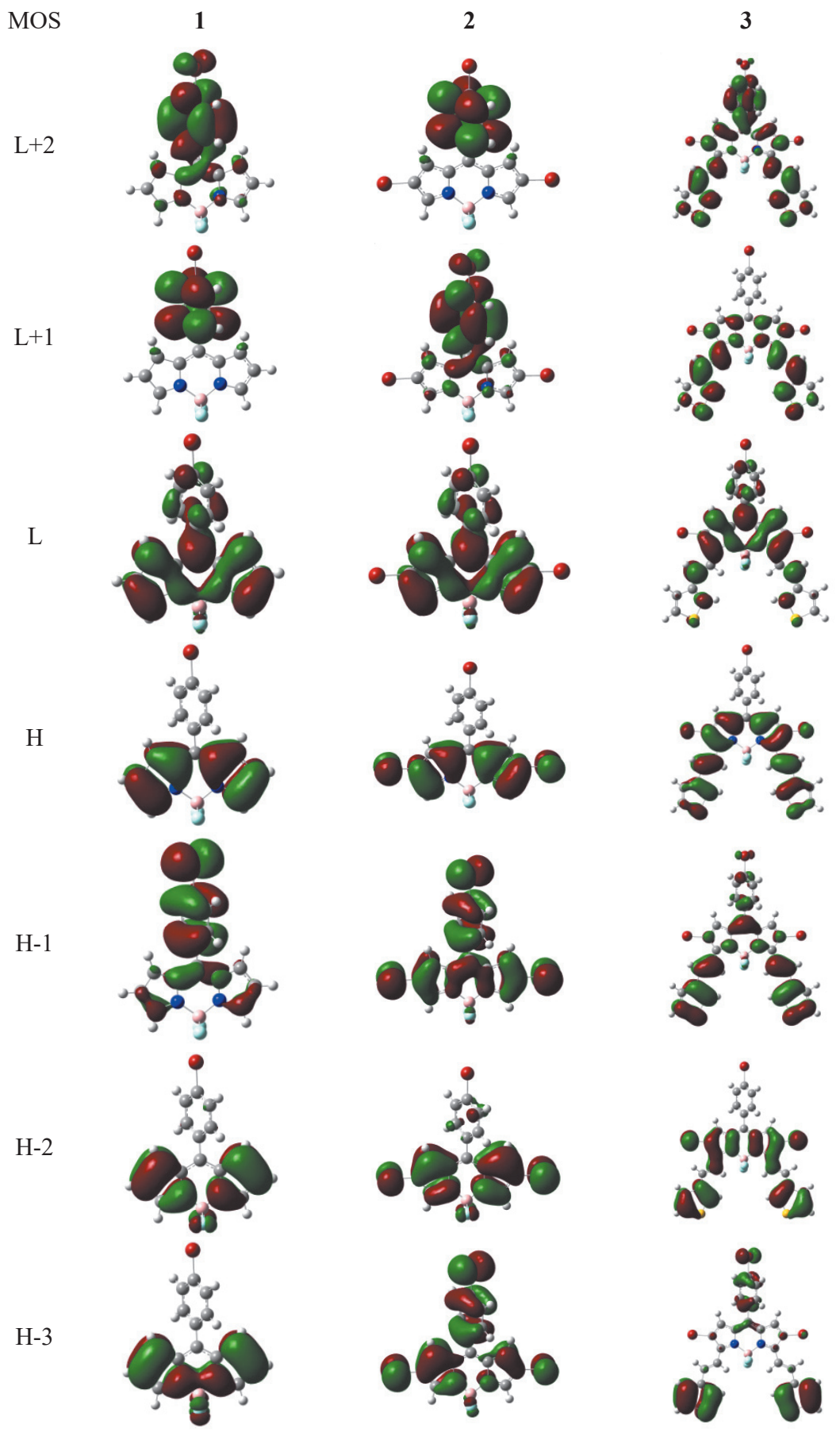

Figure 8. Frontier molecular orbitals of 1-3.

Table 3. Excitation energies, oscillator strengths and most important electronic configurations in $\%$ that span the excited state wave function of 1-3 computed at TD-CAM-B3LYP/6-31G(d) in vacuo and dichloromethane in parenthesis.

\begin{tabular}{ccccc}
\hline \# bands & Excited energies in nm & Oscillator strengths & Contribution of MOs in \% & exp \\
\hline $\mathbf{1}$ & $425.24(456.80)$ & $0.33(0.61)$ & H->L 94.23 (73.74) & 502 \\
$\mathbf{2}$ & $463.00(483.76)$ & $0.36(0.66)$ & H->L 95.54 (88.21) & 528 \\
$\mathbf{3}$ & $570.59(670.20)$ & $0.82(1.07)$ & H->L 97.35 (96.46) & 650 \\
\hline $\mathbf{1}$ & $306.28(320.89)$ & $0.43(0.53)$ & H-1->L 89.71 (83.72) \\
$\mathbf{2}$ & $315.77(341.72)$ & $0.25(0.57)$ & H-3-> L 84.74 (-) & H-1->L 7.16 (94.50) \\
& & & H-1-> L 93.93 (92.66) \\
\hline $\mathbf{3}$ & $381.05(404.78)$ & $0.87(1.59)$ & H->L 70.62 (69.13) \\
\hline
\end{tabular}


laying unoccupied orbitals of 1-3 compounds in vacuo are depicted in Table 2. The HOMO-LUMO gap of BODIPY $\mathbf{1}$ is $5.24 \mathrm{eV}$ and appears larger compare to that of $\mathbf{2}, \mathbf{3 a}$ and $\mathbf{3 b}$ estimated about 5.05, 4.00 and $3.96 \mathrm{eV}$, respectively. Thus, the substitution of $\mathrm{H}$ in $\mathbf{1}$ to form $\mathbf{2}, \mathbf{3} \mathbf{a}$ and $\mathbf{3} \mathbf{b}$ reduces the HOMO-LUMO gaps of dyes. This decrease in HOMOLUMO gap is expected to have an influence on the optical properties of these molecules. Unlike $\mathbf{2}$ in which the HOMO is stabilized by the substitution of $\mathrm{Br}$, the HOMOs of $\mathbf{3 a}$ and $\mathbf{3 b}$ are destabilized with respect to $\mathbf{1}$ (Table 2). The frontier molecular orbitals of $\mathbf{1 - 3}$ are shown in Figure 8. The HOMOs and LUMOs of the ground states of $\mathbf{1 - 3}$ are quite similar and have predominantly $\pi$ character. The LUMO +1 and $\mathrm{LUMO}+2$ are anti-bonding $\pi$-orbitals. The difference between HOMOs arises from the contribution of substituents, $\mathrm{Br}$ and CHCHC4H3S. TD-CAM-B3LYP/6-31G(d) calculations were performed to compute the optical properties of 1-3 in vacuo and in solution. Figure S3 shows the computed and experimental UV-Visible spectra of 1, 2 and $\mathbf{3}$ BODIPY structures. The computed spectra are almost similar to the normalized experimental spectra (see supporting information). Substituted $\mathbf{3}$ has large absorptivity and shift in absorption wavelengths compare to $\mathbf{2}$ and $\mathbf{1}$. Table 3 lists the excitation energies, oscillator strengths and molecular orbitals contribution on the UV-Vis spectra of 1-3 in gas phase and in solution. The deviation between experiment and TD-DFT excitation energies in dichloromethane is quite small ranging between 20 and $45 \mathrm{~nm}$. The TDDFT analysis of the most important configuration with the largest coefficient in excited state reveals that the bands observed in experiment located at $502 \mathrm{~nm}$ (1), $528 \mathrm{~nm}$ (2) and $650 \mathrm{~nm}(3)$ originate from electron transfer between the HOMO of the ground state configuration and the LUMO of the excited configuration. The superimposition of UV-Vis spectra of 1-3 computed in solvent and gas phase (see Supporting information) shows clearly that the dichloromethane influences on the UV-Vis spectra of 1-3 compounds.

\section{Conclusions}

This work was about to explore the photophysical and in vitro antibacterial activity of 2,6-dibromo-BODIPY dye substituted with dithienylenevinylene at 3,5-postions in different solvents, to assess the photodynamic inactivation activity of 2,6-dibromo-BODIPY dye alone and to understand the electronic structures including optical properties employing TD-DFT approach. Halogenated BODIPY without alkenes conjugation has shown a good PDI activity at low concentration with a small dark toxicity observed. Singlet oxygen and fluorescence quantum yields have shown that compound $\mathbf{3}$ can be used for biomedical applications. Combination of experiment and theory led to a better molecular understanding of the optical properties of these BODIPY dyes in solvent and gas phase. The computed excited energies are found in very good agreement with experimental S0->S1 excitation energies of 1-3. The deviation between experiment and computed excitation energies is quite small and is lying between $20-45 \mathrm{~nm}$. The excitation energies observed in these BODIPY UV-Visible spectra mostly originate from electron promotion between the HOMO (or HOMO-1) of the ground states to the LUMO of the excited states.

Acknowledgements. The authors thank the University of Kinshasa Hospital, Jomo Kenyatta University of Agriculture and Technology and Centre for Nanotechnology Innovation, Department of Chemistry, Rhodes University, Grahamstown 6140, South Africa for collaboration.

\section{References}

1. Hamblin M.R., Hasan T. Photochem. Photobiol. Sci. 2004, 3, $436-450$.

2. Wainwright M. Photochem. Photobiol. Sci. 2004, 3, 406-411.

3. Kim H., Kim W., Mackeyev Y., Lee G-S., Kim H-J., Tachikawa T., Hong S., Lee S., Kim J., Wilson L.J., Majima T., Alvarez P.J.J., Choi W., Lee J. Environ. Sci. Technol. 2012, 46, 9606-9613.

4. Ali H., van Lier J.E. Chem. Rev. 1999, 99, 2379-2450.

5. Drzewiecka A., Urbanska K., Matuszak Z., Pineiro M., Arnout L.G., Habdas J., Ratuszna A., Stochel G. Acta Biochim. Pol. 2001, 48, 277-282.

6. Nyman E.S., Hynnien P.H. J. Photochem. Photobiol., B 2004, $73,1-28$.

7. Detty M.R., Gibson S.L., Wagner S.J. J. Med. Chem. 2004, 47, 3897-3915.

8. Atilgan S., Ekmekci Z., Dogan A.L., Guc D., Akkaya E.U. Chem. Commun. 2006, 42, 4398-4400.

9. He H., Lo P-C., Yeung S-L., Fong W-P., Ng D.K.P. J. Med. Chem. 2011, 54, 3097-3102.

10. Kamkaew A., Lim S.H., Lee H.B., Kiev L.V., Chung L.Y., Burgess K. Chem. Soc. Rev. 2013, 42, 77-88.

11. Lim S.H., Thivierge C., Nowak-Sliwinska P., Han J., van den Bergh H., Wagnieres G., Burgess K., Lee H.B. J. Med. Chem. 2010, 53, 2865-2874.

12. Maisch T. Lasers in Medical Science 2007, 22, 83-91.

13. Wainwright M. Photodiagnosis Photodynamic Therapy 2009 , 6, 167-169.

14. Caruso E., Banfi S., Barbieri P., Leva B., Orlandi V.T. J. Photochem. Photobiol., B: Biology 2012, 114, 44-51.

15. Bartelmess J., Weare W.W. Dyes Pigm. 2013, 97, 1-8.

16. Liu Y., Li Zh., Chen L., Xie Zh. Dyes Pigm. 2017, 141, 5-12.

17. Byrne A.T., O’Connor A.E., Hall M., Murtagh J., O’Neill K., Curran K.M., Mongrain K., Rousseau J.A., Lecomte R., McGee S., Callanan J.J., O'Shea D.F., Gallagher W.M. Br. J. Cancer 2009, 2a, 1565-1573.

18. Ogunsipe A., Chen J.Y., Nyokong T. New J. Chem. 2004, 28 , 822-827.

19. Ogunsipe A., Maree D., Nyokong T. J. Mol. Struct. 2003, 650, 131-140.

20. Sibata M.N., Tedesco A.C., Marchetti J.M. Eur. J. Pharm. Sci. 2004, 23, 131-138.

21. Matheson I.B.C., Lee J. Chem. Phys. Lett. 1970, 7, 475.

22. Kuznetsova N.A., Gretsova N.S., Derkacheva V.M., Kaliya O.L., Lukyanets E.A. J. Porphyrins Phthalocyanines 2003, 7, $147-154$.

23. Kuznetsova N., Gretsova N., Kalmykova E., Makarova E., Dashkevich S., Negrimovskii V., Kaliya O., Lukyanets E. Russ. J. Gen. Chem. 2000, 70, 133-140.

24. Kaestner L., Cesson M., Kawser K., Terje C., Paul D.E., Michael J.C., Chambrier I., Jori G. Photochem. Photobiol. Sci. 2003, 2, 660-667.

25. Spiller W., Kliesch H., Wohrle D., Hackbarth S., Beateroder, Schnurpfeil G. J. Porphyrins Phthalocyanines 1998, 2, $145-158$. 
26. Ngoy B.P., Hlatshwayo Z., Nwaji N., Fomo G., Mack J., Nyokong T. J. Porphyrins Phthalocyanines 2018, 22, 413-422.

27. Fundamentals of Time-Dependent Density Functional Theory, Vol. 837 of Lecture Notes in Physics (Marques M.A.L., Maitra N.T., Nogueira F.M.S., Gross E.K.U., Rubio A., Eds.), Berlin: Springer Heidelberg, 2012. 559 p.

28. Tomasi J., Mennucci B., Cammi R. Chem. Rev. 2005, 105, 2999-3094.

29. Frisch M.J., Trucks G.W., Schlegel H.B., Ortiz G.E. Cioslowski J., Fox D.J., Wallingford CT: Gaussian, Inc. 2009.

30. Hayashi Y., Yamaguchi S., Cha W.Y., Kim D., Shinokubo H. Org. Lett. 2011, 13, 2992-2995.

31. Rurack K., Kollmannsberger M., Daub J. Angew. Chem. Int. Ed. 2001, 40, 385-387.

32. Wang S., Liu H., Mack J., Tian J., Zou B., Lu H., Li Z., Jiang J., Shen Z. Chem. Commun. 2015, 51, 13389-13392.
33. Harris J., Gai L., Kubheka G., Mack J., Nyokong T., Zhen Sh. Chem. Eur. J. 2017, 23, 14507-14514.

34. Ngoy B.P., Molupe N., Harris J., Fomo G., Mack J., Nyokong T. J. Porphyrins Phthalocyanines 2017, 21, 431-43.

35. Wardlaw J.L., Sullivan T.J., Lux C.N., Austin F.W. The Veterinary Journal, in press (electronic format available) http:// dx.doi.org/10.1016/j.tvj1.2011.09.007.

36. Ryskova L., Buchta V., Slezak R. Central Eur. J. Biology 2010, 5, 400-406.

37. Gorman A., Killoran J., O'Shea C., Kenna T., Gallagher W.M., O'Shea D.F. J. Am. Chem. Soc. 2004, 126, 10619-10631.

38. Klan P., Wirz J. Photochemistry of Organic Compounds: From Concepts to Practice. Chichester: John Wiley \& Sons Ltd., 2009.

39. Solovyov K.N., Borisevich E.A. Phys. Usp. 2005, 48, 231253. 